\title{
A Framework for Disaster Vulnerability in a Small Island in the Southwest Pacific: A Case Study of Emae Island, Vanuatu
}

\author{
Guy Jackson $^{1} \cdot$ Karen McNamara $^{1} \cdot$ Bradd Witt $^{1}$
}

Published online: 3 October 2017

(c) The Author(s) 2017. This article is an open access publication

\begin{abstract}
The societal costs of disasters around the world are continuing to increase and Pacific Island countries are considered some of the most vulnerable. This is primarily due to a combination of high hazard exposure coupled with a range of social, economic, physical, and political vulnerabilities. This article contributes to the growing body of work that aims to understand the causal factors of disaster vulnerability, but with a specific focus on small island developing states. The article first develops a framework for understanding disaster vulnerability, drawing on extensive literature and the well-established Methods for the Improvement of Vulnerability in Europe (MOVE) framework, and second, applies this adapted framework using empirically-derived data from fieldwork on Emae Island, Vanuatu to provide a working understanding of the causal elements of disaster vulnerability. Drawn from a significant body of scholarship at the time, the MOVE framework was primarily developed as a heuristic tool in which disaster vulnerability is considered to be a function of exposure, susceptibility (socially, economically, physically, culturally, environmentally, institutionally), and a lack of resilience. We posit that this adapted framework for small islands should also include historical susceptibility, and we prefer livelihood resilience (as capabilities, social capital, knowledge, participation, and human rights) over lack of resilience. We maintain that understanding disaster vulnerability holistically, which is inclusive of both strengths and drawbacks, is crucial to ensure that limited resources can target the causal factors that produce
\end{abstract}

Guy Jackson

guy.jackson@uq.edu.au

1 School of Earth and Environmental Science, The University of Queensland, Brisbane, QLD 4072, Australia vulnerability and help safeguard and improve livelihoods in both the short and long term.

Keywords Disaster risk reduction - Disaster vulnerability $\cdot$ Livelihood resilience $\cdot$ Small islands · Vanuatu

\section{Introduction}

The historical development of disaster studies can be simplified into a dichotomy based on paradigmatic differences in how disasters and their management have been conceptualized (Gaillard and Mercer 2012). The dichotomy is based on the hazard versus vulnerability paradigm. The "hazard paradigm" focuses on behavioral interpretations (Kates 1971), while the "vulnerability paradigm" draws on a human/political ecological interpretation (Hewitt 1983; O'Keefe et al. 1976; Wisner et al. 2004). Simplifying disaster studies into this dichotomy, however, runs the risk of over simplifying a complex set of literature and concepts and this is acknowledged.

The hazard paradigm was strongly influenced by the behavioral geography movement and is considered to be the first contemporary paradigm (Gaillard and Mercer 2012). This paradigm considered disasters to be the result of natural hazards in which the population affected failed to adjust due to being unprepared or was unaware of the risk it was exposed to (Kates 1971). Gaillard and Mercer (2012) suggest that the hazard paradigm focused on the physical hazard itself and was mainly driven by science- and technology-driven mitigation measures, such as early warning systems, engineered defences, and other structural methods such as building codes and land-use planning - referred to by Hewitt (1983) as a physicalist paradigm. As the hazards 
paradigm grew from within the United States and spread throughout the developed world, the technocratic approach, based upon centralized modern states, showed little consideration for the developing world (Quarentelli 1987).

A competing paradigm that emerged in the 1970s from a human/political ecological perspective can be broadly labelled the vulnerability paradigm (O'Keefe et al. 1976; Hewitt 1983). The key difference is that the vulnerability paradigm suggests that disasters primarily affect marginalized groups who lack access to resources and means of protection that are available to the more powerful (Hewitt 1983). Disasters were increasing around the world throughout the 1970s without a significant increase in the number of hazards-some researchers considered this as evidence of the link between unequal socioeconomic development and disasters (O'Keefe et al. 1976). Focusing on the socially constructed vulnerability of an exposed population equally has allowed for a more nuanced sociological perspective that was not present in the earlier hazard paradigm.

The hazard paradigm continues to be dominant at international and national levels, with Lavell and Maskrey (2014) suggesting that globally many actors and institutions still equate disasters as natural as opposed to resulting from socially driven vulnerability. The conceptual difference between the hazard and vulnerability paradigms affects the way modern disaster risk reduction (DRR) is ultimately implemented. Underlying social causes of vulnerability will not be addressed if a disaster is framed as "natural", which will lead to reactive management processes. Although "natural disasters" is an established term, many authors have stressed that disasters are not natural, but rather they are endogenous to human society and only arise when hazards interact with the physical and social vulnerabilities of an exposed population (Bogard 1988; Chambers 1989; Watts and Bohle 1993; Cutter 1996; Weichselgartner 2001; Ferdinand et al. 2012; Oliver-Smith 2013; Aitsi-Selmi et al. 2015). The separation of disasters from the broader social-cultural, economic, environmental, and political contexts, as well as from issues such as poverty, globalization, and climate change, has been acknowledged as a barrier to the effectiveness of DRR strategies in reducing vulnerability (Schipper and Pelling 2006; Weichselgartner and Pigeon 2015).

\subsection{Towards a Causal Disaster Vulnerability Framework}

In the following sections, we build an adapted framework to generate a working understanding of casual factors of disaster vulnerability in small island contexts. First, the term disaster vulnerability is discussed in relation to the literature as we work towards a final set of conditions for use in our framework. Second, resilience as a concept is briefly explored, including the growth of the term and the sustained criticism of various interpretations, to arrive at a concept that takes a livelihood framing. Lastly, our interpretation of vulnerability and resilience are adapted to the Methods for the Improvement of Vulnerability in Europe (MOVE) framework (Birkmann et al. 2013) before being tried out in the rural developing nation context of Emae Island, Vanuatu.

Extrapolating root causes of vulnerability has remained a point of enquiry and contention over time (Weichselgartner 2001), and a full exploration of the history of vulnerability is beyond the scope of this research. The more specific "vulnerability to hazards and climate change" has been a focal area of interdisciplinary research over the last few decades (Cutter 1996; Morrow 1999; Pelling and Uitto 2001; Cutter et al. 2003; Eriksen and O'Brien 2007; O'Brien et al. 2007; Ribot 2011; Kelman et al. 2015). As such, researchers have proposed numerous frameworks and assessments in an attempt to capture the now acknowledged physical and social dimensions of vulnerability in developed (Fuller and Pincetl 2014) and developing country contexts (Boruff and Cutter 2007; Turvey 2007; Djalante et al. 2013). Underlying most conceptions of disaster or climate vulnerability is that it involves exposure of social and physical attributes along with their propensity to suffer harm against a specific hazard or process. These components are encapsulated in the Inter-Governmental Panel on Climate Change (IPCC) (Cardona et al. 2012) definition where climate vulnerability is considered a function of exposure, sensitivity, and adaptive capacity. While the underlying premise for vulnerability is generally agreed on, there is a divergence on the interpretation and application (Weichselgartner 2001). This may stem from various actors' perceptions of hazards as discrete exogenous events (Lavell and Maskrey 2014), whereas vulnerability is a socially constructed continuum that hazards interact with (Weichselgartner 2001; Lewis 2014; Oliver-Smith et al. 2016). Oliver-Smith et al. (2016, p. 8) captures the latter position succinctly: "disaster risk and eventual disaster are social constructs based on the presence of potentially damaging physical events but seriously and dominantly conditioned by societal perceptions, priorities, needs, demands, decisions and practices". In addition, vulnerability must take an "over time analysis," which is well represented by the "historical construction" of disaster risk, in which the historical processes that contributed to the severity of the disaster are considered (Oliver-Smith 2010; Tobin 2013). We take these conditions of disaster vulnerability, built over decades of research, forward as we continue to build our casual disaster vulnerability framework by next exploring the contested term resilience. 
While the history of the term resilience in DRR is complex (Alexander 2013), the first modern interpretation for ecology can be traced to Holling (1973, p. 17) in which he defined ecological resilience as: "the persistence of relationships within a system; a measure of the ability of systems to absorb changes of state variables, driving variables, and parameters, and still persist." From this initial conception, resilience has been used liberally to represent different social and physical phenomena (Cutter et al. 2008). The most common approach is epitomized by Paton and Johnston (2001, p. 273) in which resilience to environmental hazards at the community level is described as: "the capability to bounce back and to use physical and economic resources effectively to aid recovery following exposure to hazards." Nevertheless, the term "bounce back" itself reveals the physical science roots that lay embedded within the concept (Holling 1973; Paton and Johnston 2001), and tends to elicit images of a composite material returning to its original state after being distorted. This reading of resilience would lead to a return to a predisaster state, which would recreate the causes of vulnerabilities that resulted in a disaster to begin with. Despite this logical criticism, the physical science view of resilience in social-ecological systems became a dominant paradigm, which is well represented through the work of Folke (2006). Researchers are beginning to address this contradiction through concepts such as "build back better," which is becoming more established in the literature (Mannakkara and Wilkinson 2015). However, there are criticisms of the feasibility of such concepts when operationalizing them, due to possible constraints to capacities caused by poverty, weak institutions, or unproductive environments, among other examples (Jauhola 2015). There also have been sustained criticisms regarding the applicability of resilience in the social sciences more broadly due to its possible role in depoliticizing complex social-political causes of vulnerability (Olsson et al. 2015).

Disasters may reveal and accentuate deep rooted poverty (Tobin 2013), result in political change (Kelman 2012), or any number of outcomes (Méheux et al. 2006). As such, trying to measure resilience remains conceptually challenging (Olsson et al. 2015). The most prevalent method is to use a baseline of pre-event function and then measure subsequent change to provide insight into how the disaster, as a discrete event, directly impacts, for example, health, infrastructure, and food systems along with social response mechanisms. In contrast, by analyzing livelihoods over time, including elements such as capabilities, social capital, knowledge, participation, and human rights, a far more realistic picture of resilience to disturbances will likely emerge (Tanner et al. 2014).

As research continues to suggest that theoretically and practically climate change adaptation (CCA), DRR, and development overlap (Kelman et al. 2015), we will use the bridging concept of livelihood resilience for our framework (Tanner et al. 2014). This is a human-centered conception of resilience that is defined by Tanner et al. (2014, p. 23) as: "the capacity of all people across generations to sustain and improve their livelihood opportunities and well-being despite environmental, economic, social and political disturbances." Tanner et al. (2014, p. 23) suggested that livelihood resilience is informed by: "human agency and empowerment, individual and collective action, and by human rights, set within the dynamic processes of social transformation." This approach to resilience reflects the potential for adaptation against what Kelman et al. (2015) have aptly labelled multiple exposures from multiple threats. Reframing resilience around livelihoods is important, for a livelihood is more than just income, it reflects any activity that maintains the household or community, be it subsistence agriculture, production, trade, or labor, while also accounting for other key resources such as social networks and ecosystem services (Ifejika Speranza et al. 2014). Therefore, in our causal disaster vulnerability framework, livelihood resilience will be used, with the caveat that there are real limitations to the use of resilience that will be acknowledged and expanded upon throughout the article.

\subsection{Adapting the MOVE Framework}

Disaster vulnerability is a social construct that must be considered over time (Oliver-Smith 2010), and resilience is well represented by livelihood resilience (Tanner et al. 2014). With these preconditions, we build on the MOVE framework, which was developed as a heuristic tool to outline the key dimensions of disaster vulnerability and built over many years of research (O'Keefe et al. 1976; Cutter 1996; Weichselgartner 2001).

The MOVE framework, like the Intergovernmental Panel on Climate Change (IPCC) definition, considers vulnerability to be a function of exposure, susceptibility, and adaptive capacity (framed as lack of resilience or societal response mechanisms). Fixed physical (for example, infrastructure) and social (for example, livelihoods, economy, and culture) attributes of the population, which are dependent on specific resources and practices, are used to represent potentially exposed assets. The exposed physical and social attributes are then considered susceptible if they are likely to suffer harm during a hazard event. Finally, lack of resilience or societal response capabilities is used to express the limitations in terms of "access to and mobilization of the resources of a community or a socialecological system in responding to an identified hazard" (Birkmann et al. 2013, p. 200). Based on our previous argument in favor of a livelihoods framework that draws on 
strengths as well as stresses, our adapted framework replaces lack of resilience (adaptive capacity) with livelihood resilience that comprises the following indicators: knowledge, information, and resource flows; participation in formal and informal decision-making processes; capabilities, agency, assets, and activities required for a means of living; social capital; and human rights.

Social, economic, physical, cultural, environmental, and institutional dimensions are included in the MOVE framework, which posits that the susceptibility of exposed physical and social assets is multidimensional. The social dimension represents the propensity for a loss of well-being, either individual (for example, mental or physical health) or collective (for example, services) and the characteristics of those most affected (for example, groups marginalized by virtue of race, ethnicity, or gender). The economic dimension represents the propensity for loss of economic value due to physical damage or the loss of productive capacity. The physical dimension includes the propensity for damage to infrastructure or other fixed assets. The cultural dimension is defined as the potential for damage to intangible values including meanings placed on artefacts, customs, habitual practices, and natural or urban landscapes. The environmental dimension expresses the potential damage to ecological and biophysical systems and their function (for example, ecosystem services). Finally, the institutional dimension is the potential damage to governance systems, formal and informal, due to exposed weakness following a disaster. The one area of susceptibility that is inadequately represented in the original MOVE framework is the historical considerations. As such, we include the historical dimension, which we base on the formulation by Oliver-Smith (2010). The historical dimension asks what historical actions or processes led to the severity of a disaster. Asking and answering questions over time will add depth and causality to our adapted framework. In summary, drawing on the MOVE framework, Oliver-Smith (2010), and Tanner et al. (2014), we posit that disaster vulnerability is, conceptually, a function of the dimensions outlined in Fig. 1.

In this adapted framework, the physical and social assets that are exposed to hazards will be identified by previous hazard impacts and communities' experience. Susceptibility of the exposed assets can be understood by exploring the historical, social, economic, physical, cultural, environmental, and institutional dimensions of susceptibility. The identified susceptibility can be evaluated against the level of livelihood resilience (with the caveat of real limitations) comprising the following attributes: knowledge, information, and resource flows; participation in formal and informal decision-making processes; capabilities, agency, assets, and activities required for a means of living; social capital; and human rights.
The MOVE framework has thus far been applied quantitatively using a range of socioeconomic and socioecological indicators for different hazards and settings (Depietri et al. 2013; Welle et al. 2014; Kablan et al. 2017). Our adapted MOVE framework is applied qualitatively in a small island in the South Pacific.

\subsection{Small Island Developing States}

Small island developing states (SIDS), while heterogeneous, share certain features and characteristics relating to vulnerability to environmental, social, political, and economic disturbance (Pelling and Uitto 2001; Julca and Paddison 2009). For example, small islands by their nature are limited: their small size and restricted resource base, high exposure to hazards and climate change (Lewis 1990; Betzold 2015), great distance from major population centers and resources (plus subsequent economic costs incurred to overcome relative isolation), and limited economic opportunities (Briguglio 1995; Encontre 1999) are common characteristics. Global change, holistically, is affecting SIDS in multifaceted ways-for instance, although many changes have been deleterious, novel opportunities have also emerged (Pelling and Uitto 2001). There has also been an overwhelming focus on climate change adaptation in SIDS, possibly to the detriment of underlying root causes of vulnerability by depoliticizing many of the processes that continue to weaken the ability of states to confront these challenges on their own terms (Kelman 2014).

\subsection{South Pacific Disaster Risk}

The South Pacific is considered one of the most hazardprone regions in the world (Garschagen et al. 2016). This is attributed to high levels of exposure to hazards (Solomon and Forbes 1999; Noy 2015) coupled with a range of vulnerabilities that include low economic development, weak formal governance structures and social protection, and a dependence on exposed assets and entire industries, such as agriculture and fisheries, that are crucial for livelihoods (Barnett 2010; Connell 2010, 2015; Cobon et al. 2016). Climate change also poses a greater risk of hazards in the South Pacific: increasing intensity of cyclones (despite a possible decrease in the number (Knutson et al. 2010; Walsh 2015); sea level rise; an increased frequency of $\mathrm{El} \mathrm{Niño-Southern} \mathrm{Oscillation}$ (ENSO) cycles (Cai et al. 2014); changing rainfall patterns and increased temperatures, among others (Hansen and Stone 2015). Faced with these present and future threats, improving the management of "natural disasters" has become a central theme in policy throughout the South Pacific, including Vanuatu where this research is based. 
Fig. 1 Dimensions of disaster vulnerability as affected by exposure, susceptibility, and livelihood resilience. Source: Adapted from the MOVE framework (Birkmann et al. 2013), and the concepts of livelihood resilience (Tanner et al. 2014) and "historical construction of disasters" (Oliver-smith 2010)

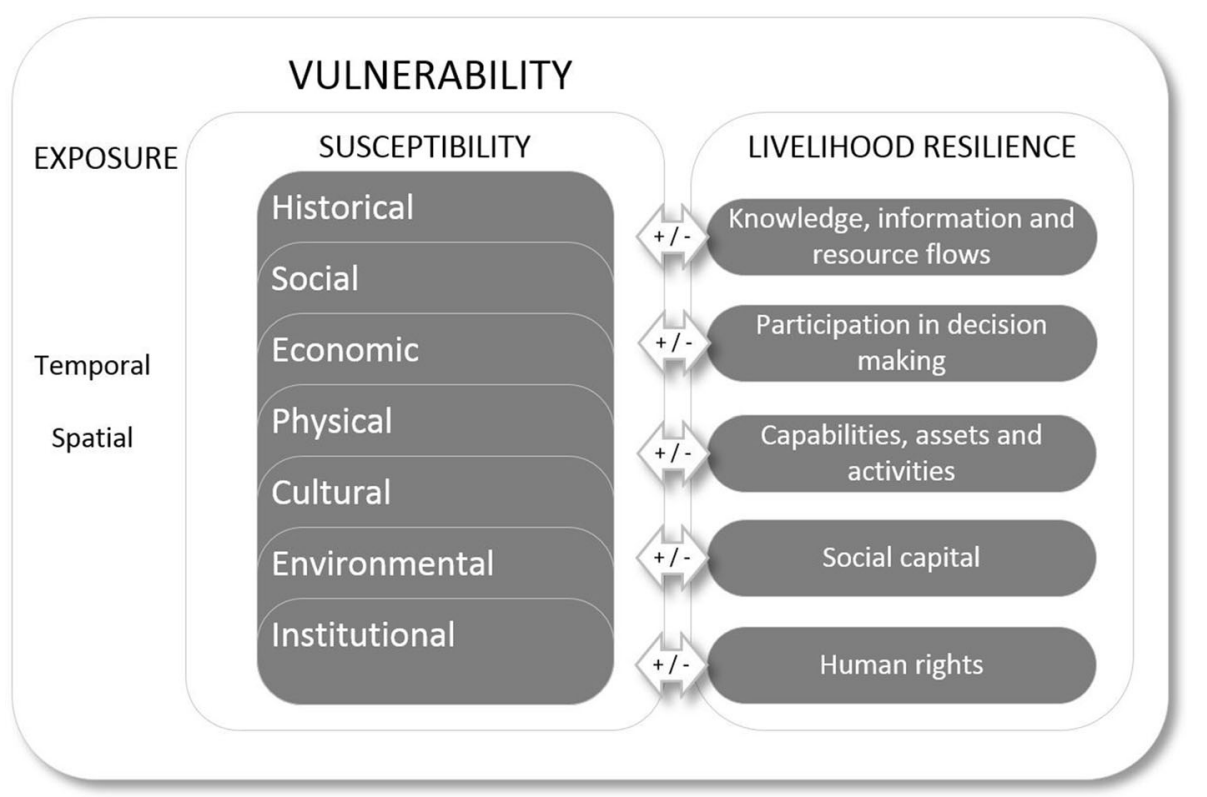

The destructive impact of category five cyclones Pam (March 2015) in Vanuatu and Winston (February 2016) in Fiji may be indicative of the type of hazards associated with climate change. The capacity of rural Vanuatu communities to cope with such powerful cyclones is low (SPC 2015), which can be observed from the post-recovery period. Homes, infrastructure, crops, and fisheries were severely impacted, causing widespread disruption to the communities affected. Although relief operations are currently needed, they remain reactive and the Sendai Framework advocates placing more focus on DRR, which should be targeted at underlying casual factors of disaster vulnerability (UNISDR 2015). There are also many other severe hazards in the region such as droughts, floods, earthquakes, king tides, landslides, fires, volcanoes, among others, which must be considered in any DRR strategy (SPC 2015).

\subsection{Study Aims}

The study had two inter-linked aims. The first was to develop a framework for understanding causal factors of disaster vulnerability in the context of small island developing states by drawing on relevant literature and the wellestablished MOVE framework. The second goal was to apply this adapted framework to a rural community in a small island in the southwestern Pacific. These objectives were accomplished by engaging in fieldwork on Emae Island, Vanuatu.

\section{Methods and Study Site}

Driven by the adapted disaster vulnerability framework (Fig. 1), we used an array of qualitative methods including semistructured interviews, informal discussions, and participatory hazard mapping, to collect qualitative data on Emae Island, Vanuatu in early 2016. In the local context, informal methods proved to be particularly valuable as they aligned with local sociocultural norms surrounding the exchange of information. This section outlines the methods employed and finishes with an introduction to the study site.

\subsection{Interviews, Informal Discussions, and Participant Observation}

Data collection on Emae Island, Vanuatu took place over a 5-week period in early 2016. Semistructured interviews with key informants were used due to the ability of this process to ensure flexibility in respondent response, while still being informed by the conceptual framework and research aim (Semali et al. 2007; Schischka et al. 2008). These beneficial attributes are reinforced by Dunn (2000, p. 200), who suggests that semistructured interviews have "some degree of predetermined order but still ensures flexibility in the way issues are addressed by the informant." They were also more culturally acceptable in relation to norms and values on Emae Island, in which discussions, even serious, were approached in an open manner, with interjections from other community members, arguments, and anecdotes used by those involved. The value of using culturally appropriate methods is vital 
in engagement with indigenous communities (see Semali et al. 2007).

In total, 14 semistructured interviews were conducted, as follows: 5 Emae Island key disaster informants (health, education, international nongovernmental organization (INGO), disaster committee, and disaster chairman, all male); 5 Vanuatu national and provincial informants (responsible for Emae DRR, 2 males and 3 females); and 4 leaders of nongovernmental organizations (NGOs) and intergovernmental organizations (all familiar with Shefa Province, all male). Informants were chosen to represent key areas of DRR. For example, on Emae those that identified as having a major role in disaster management were selected, the government informants were suggested through consultation with local DRR stakeholders, and NGOs were approached ad hoc, yet they all operated in the Emae region.

Although our formal sample size is small, with definite limitations, interviews were strategically utilized to counterbalance the large number of informal discussions $(n=80+)$ with local community members (men and women), along with participant observation and immersion in Emae village life. Interviews averaged $40 \mathrm{~min}$, but ranged from $20 \mathrm{~min}$ to $1.5 \mathrm{~h}$. An interview guide was used, although interview questions were adapted to relate to the experience of the informants. Interviews were undertaken in English and Bislama (national creole language). A digital recorder was used to capture interview data, which was later transcribed into NVivo. ${ }^{1}$ Translation of Bislama interviews was undertaken by the lead author, with the assistance and advice from the gatekeeper of this study (a translator by previous profession). The gatekeeper is a chief of Tongamea village, Emae (see Fig. 2), who, at the time fieldwork was undertaken, was the Vanuatu consul in New Caledonia. He assisted the research team by organizing accommodation, letters of introduction for government ministries, and by making Emae locals aware of the research topic. Having access through a village chief may have influenced the informants and the information they provided, but every effort was taken to minimize bias and only the dominant themes were considered for use. For instance, semistructured interviews were contrasted with informal discussions and observations to identify themes, while a wide range of discussions from people from villages not under the gatekeeper's influence helped to tease out potential biases.

The informal discussions included locals sharing their personal experiences of various disaster events over time,

\footnotetext{
${ }^{1}$ NVivo is a qualitative and mixed methods coding program that enables the detailed analysis of data to reveal relationships and themes. Please visit http://www.qsrinternational.com/nvivo-product for more information.
}

including the impact of such events on food systems and infrastructure and ways of responding both to internal and external assistance. These discussions also included people's observations about changes in the local environment, culture, and traditions, and explored how they use their traditional/local knowledge to manage local environmental change, among other broad livelihood topic areas. Such discussions were primarily undertaken in groups throughout the day. For example, when a group of fishermen arrived back in Tongamea village, the lead author approached them and asked to speak about their catch, which led to a 2-h discussion on issues such as fish stocks, prices, and perceived environmental changes. Other informal research techniques included transect walks with members of community disaster committees to identify hazard exposure based on previous hazard impacts.

Participant observation was also used during fieldwork. Although a broad research method, participant observation allows for improved context-specific understanding and provides a richness of detail that compliments other data. For this research, participant observation involved keeping a detailed journal that recorded visual and verbal observations, details of the informal discussions, conceptual diagrams, and newspaper stories (Özerdem and Bowd 2009; Ray-Bennett 2009; Vo 2015).

\subsection{Data Analysis and Study Limitations}

Qualitative data collected were analyzed using NVivo. Only the most prominent themes from interviews, informal discussions, and participant observation are included in the results. Quotes from interviews are used to represent wider themes from all data collected. The adapted MOVE framework was used to inform the analysis. Codes are used for the Emae key informant interviews and are presented after quotes to identify informants' related fields and relevance. The code is as follows: $\mathrm{H}=$ Healthcare; $\mathrm{E}=$ Education; $\mathrm{DM}=$ Disaster Manager; $\mathrm{EP}=$ Environmental Program (indigenous NGO); and $\mathrm{DC}=$ Disaster Committee.

Although the small sample size of interviews raises valid concerns, the formal interviewees were selected strategically to target specific DRR stakeholders. In hindsight, more formal interviews would have strengthened the conclusions drawn from this research, but the triangulation with participant observation, transect walks, and the large number of informal discussions improves the reliability of the data. This study had limited resources, and does not claim to be definitive. The primary motive for the research was to apply current theory and frameworks in a field research setting. This was done in an embedded manner and generated a working, not a complete, understanding of 


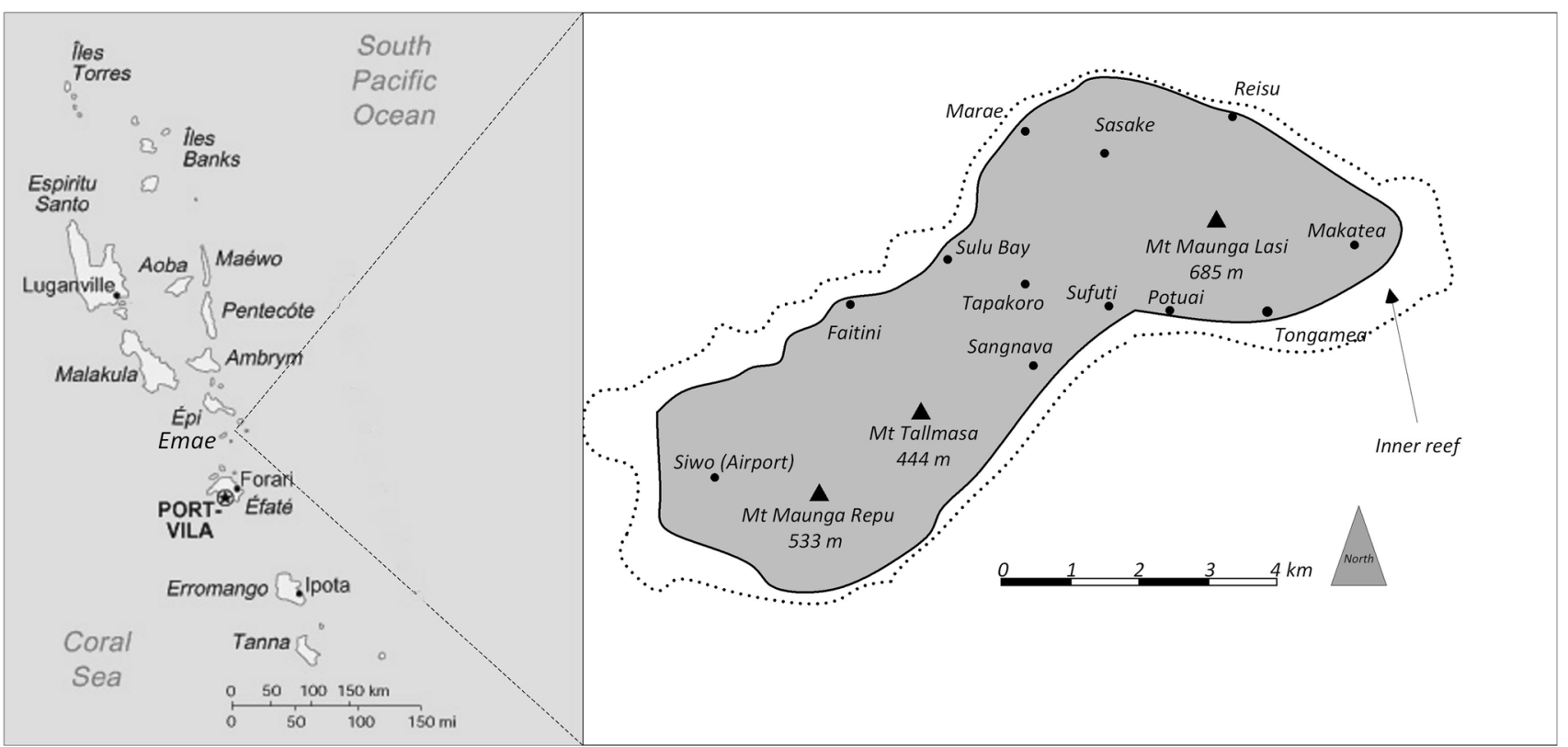

Fig. 2 Emae Island location in relation to Vanuatu and a map of Emae including locally derived names of villages and mountains

the causal factors of disaster vulnerability that impact Emae communities.

\subsection{Study Site}

The study was undertaken on Emae Island, which is located $17^{\circ} 4^{\prime} \mathrm{S}$ and $168^{\circ} 24^{\prime} \mathrm{E}$ in Shefa Province, Vanuatu (Fig. 2). It is part of the Shepherd Islands, including Emae, Mataso, Makura, Tongariki, Laika, and Tongoa. Emae is a small island $\left(32 \mathrm{~km}^{2}\right)$ of volcanic origin with three large mountains in the interior, the largest being Maunga Lasi (685 m) with villages primarily located around the coastal fringe. Emae has a population of roughly 900 people although this fluctuates with intrastate and interstate migration and returns. Emae inhabitants speak a Polynesian derived language called Fakamae (Capell 1962) although all speak Bislama, the national croele english language. Primary livelihood strategies are coastal resource collection, subsistence agriculture, and remittances. Income generation is increasing in perceived importance and is derived through the export of fish and crops to Port Vila and remittances. Recent disasters, cyclone Pam in March 2015 and the El Niño drought that was active during the fieldwork, have detrimentally affected livelihood strategies on Emae, with a perceived increased need for aid from donors. Emae shares similarities with rural islands in Vanuatu that have limited tourism, are politically weak, and have sustained contact with NGOs. Importantly, traditional custom governance is still strong, although rapid social and cultural change is continuing to take place, which has been identified in other rural parts of the country (Westoby 2010). As such, Emae may, with caution, be used as an example of other islands in Vanuatu that share the characteristics described above.

\section{Emae Communities' Exposure to Hazards}

The interviews and other data revealed that many social and physical assets on Emae are highly exposed to environmental hazards. Informants identified cyclones and an increased incidence of drought as their key disaster concerns. Table 1 presents Emae communities' experiences of hazards over time in descending order of perceived exposure.

\section{Susceptibility to Disasters}

This section illustrates how Emae communities' susceptibility to disasters is based on various dimensions, including: historical, social, economic, physical, cultural, environmental, and institutional. Emae's susceptibility to disasters is primarily represented by the impacts following cyclone Pam, along with some examples of the 2015/2016 El Niño drought that was being experienced during the fieldwork. Table 2 presents the key themes that emerged from data coding, which is followed by a discussion of each.

The historical dimension captures historical processes that contributed to the severity of a disaster. Based on the fieldwork, village and infrastructure location, building, and 
Table 1 Emae community perceptions of hazard exposure

\begin{tabular}{|c|c|c|}
\hline Hazard & General frequency of events & Current perception by communities \\
\hline $\begin{array}{l}\text { Tropical } \\
\text { cyclone }\end{array}$ & $\begin{array}{l}\text { Since } 1972 \text { informants claimed that there had been five } \\
\text { destructive cyclones. With cyclone Pam (2015) and cyclone } \\
\text { Prema (1993) causing the most damage }\end{array}$ & $\begin{array}{l}\text { Due to the fieldwork taking place } 11 \text { months after cyclone Pam } \\
\text { (March 2015) that devastated Emae, cyclones were perceived } \\
\text { to be a major threat. Most DRR was related to cyclone } \\
\text { preparation and response }\end{array}$ \\
\hline Drought & $\begin{array}{l}\text { There were frequent droughts from minor to extreme severity. } \\
\text { Generally, they follow ENSO cycles as was evidenced by the } \\
\text { severe drought during El Niño phase throughout the fieldwork } \\
\text { (2016), but often occur in the dry season }\end{array}$ & $\begin{array}{l}\text { During fieldwork, water security was perceived to be the largest } \\
\text { concern for communities on Emae. Elders spoke of many } \\
\text { previous droughts and their impact on gardens and social } \\
\text { well-being more generally }\end{array}$ \\
\hline Flooding & $\begin{array}{l}\text { Major recent flooding events were said to have occurred in } \\
\text { 2000, 2010, and 2015. Damaging events primarily related to } \\
\text { storm surges and flash flooding }\end{array}$ & $\begin{array}{l}\text { Storm surges, king tides, and intense precipitation events } \\
\text { leading to flooding of villages were said to be common } \\
\text { occurrences by Emae inhabitants. Structural methods and } \\
\text { coastal retreat were discussed and demonstrates the } \\
\text { communities' awareness of coastal risks }\end{array}$ \\
\hline Landslide & $\begin{array}{l}\text { From the responses of the informants landslides are a common } \\
\text { hazard. While severe landslides have occurred recently (in } \\
\text { Vaima and Marae in 2010, many villages in 2015), they are } \\
\text { not that frequent }\end{array}$ & $\begin{array}{l}\text { On an island with three large dormant volcanic mountains, } \\
\text { landslides are common and communities understand the risk. } \\
\text { For example, the village of Vaima was buried in } 2010 \text { and } \\
\text { Marae was impacted. Precipitation from cyclones was often, } \\
\text { though not exclusively, the cause }\end{array}$ \\
\hline Tsunami & $\begin{array}{l}\text { In } 1978 \text { a large tsunami impacted the northeastern villages and } \\
\text { destroyed the then coastally situated village of Makatea }\end{array}$ & $\begin{array}{l}\text { There were an awareness of the risk and many extant stories of } \\
\text { the } 1978 \text { tsunami. Tsunami alerts are sent via radio and text }\end{array}$ \\
\hline Earthquake & $\begin{array}{l}\text { Minor earthquakes were reported by all informants in living } \\
\text { memory }\end{array}$ & $\begin{array}{l}\text { There was little emphasis on earthquakes during discussions } \\
\text { about hazards. The islanders understand the link between } \\
\text { earthquakes and tsunamis and the DRR coordinator explained } \\
\text { evacuations can be ordered }\end{array}$ \\
\hline Fire & $\begin{array}{l}\text { There have been fires in informants' experience with } 1991 \\
\text { standing out as particularly severe }\end{array}$ & $\begin{array}{l}\text { Fire was understood to be a hazard with most adults having } \\
\text { direct experience, but the risk was considered low }\end{array}$ \\
\hline
\end{tabular}

design were critical in understanding the widespread losses during cyclone Pam in 2015 and previous events. The key theme that emerged was the 1952 relocation of villages during the condominium period. A Tongamea disaster committee informant explained the well-known story:

Oldfala station that we saw before, they stayed at that place there but they faced difficulties with water [and so] the two missionaries, and the two British and French governments, colonial eh, they came and said you fala's [people] must move out from the oldfala station and then come down to the new station (DC).

This "new station" is where Tongamea is situated today close to the shoreline. The relocation was repeated in other villages around Emae, such as Makatea. A tsunami in 1978 decimated Makatea. The community relocated further up Mount Maunga Lasi on the site where they previously resided. This type of vulnerability has been called the "historical construction of vulnerability" by Oliver-Smith (2010, p. 36) in relation to the Haiti earthquake.

The social dimension represents a loss of individual or collective well-being due to a disaster. The data suggest that cyclone Pam caused widespread disruption to services on Emae; education and community health initiatives were suspended for just over 2 weeks. Furthermore, water concerns due to the El Niño drought (2015/2016) amplified the damage from cyclone Pam. When the fieldwork took place, water tables were dropping, salinity increasing, and crops were stunted or failing completely. A key stakeholder in education captures the impact of cyclone Pam on water, food, and education:

Time when all children walkabout the road, this time of year, sun can be very hot. After all of them are needing water. After cyclone Pam, the water that belongs to you and me was not very good. I had to stop class sometimes, half days, and then we'd eat all together, sometimes we tell the children not to come to school tomorrow because we don't have enough food $(\mathrm{E})$.

Other key themes included high prevalence of noncommunicable diseases throughout the adult population that was straining healthcare resources, which was affecting susceptibility against all manner of shocks or disturbances $(\mathrm{H})$. General discussions also revealed the perceived loss of independence due to a reliance on aid (particularly after disasters and other shocks). 
Table 2 Major themes for each susceptibility dimension of disaster vulnerability

\begin{tabular}{|c|c|}
\hline Dimension & Themes represented as susceptibility as a dimension of disaster vulnerability \\
\hline Historical & $\begin{array}{l}\text { Relocation of villages to shoreline } \\
\text { Population growth } \\
\text { Resource diminishment } \\
\text { Changing lifestyles }\end{array}$ \\
\hline Social & $\begin{array}{l}\text { Disaster impact on health } \\
\text { Water security } \\
\text { Disaster impact on education } \\
\text { Losing self-reliance }\end{array}$ \\
\hline Economic & $\begin{array}{l}\text { Economic impact from cyclone Pam } \\
\text { Perceived increased need for money to access goods and services } \\
\text { Lack of funding for programs (for example, DRR, climate change adaptation, and development) and a } \\
\text { dependence on volunteers } \\
\text { Desire for other economic activities }\end{array}$ \\
\hline Physical & $\begin{array}{l}\text { Infrastructure: location and design } \\
\text { Lack of safe houses/evacuation centers } \\
\text { Loss of communications } \\
\text { Loss of coastal tree cover }\end{array}$ \\
\hline Cultural & $\begin{array}{l}\text { Loss of ecosystem services (impact on five customary elements: yams, pigs, mats, kava, and bananas) } \\
\text { Spiritual connection with land impacted by disasters }\end{array}$ \\
\hline Environmental & $\begin{array}{l}\text { Climate change } \\
\text { Impact from cyclone Pam } \\
\text { Ecosystem services } \\
\text { Resources diminishment } \\
\text { Water security }\end{array}$ \\
\hline Institutional & $\begin{array}{l}\text { Weakening traditional practices } \\
\text { Community/land disputes } \\
\text { Weak national institutions } \\
\text { Changing community structure }\end{array}$ \\
\hline
\end{tabular}

The economic dimension represents the propensity for loss of economic value due to physical damage or the loss of productive capacity. The impact from disasters were expressed through the severe drop in income-earning resources after cyclone Pam and an increased dependence on fisheries for income generation and subsistence (EP 4). Prior to cyclone Pam Emae livelihoods were sustained through fisheries (50\%), agriculture (30\%), and livestock $(20 \%)$, while a key informant stated that:

After the cyclone [Pam], this time we live off $90 \%$ fisheries, and also 5\% agriculture, and also another $5 \%$ from livestock. Livestock has dropped. And also agriculture has dropped and gone down, these people are relying more on marine resources (EP).

Income generation as a livelihood strategy was suggested to have increased in importance over time, primarily to pay for school fees, imported food, building materials, and nonessential luxury items. Interviews and informal discussions revealed other key themes that include a dependence on volunteers from the local communities for DRR, climate change adaptation (CCA), and development programs and strategies, along with the perception that incomes must be diversified to prevent future disruptions in the local economy such as those experienced after cyclone Pam and during the El Niño drought.

The physical dimension of susceptibility is expressed as the propensity for damage to infrastructure or other fixed assets. Most villages are located on the coastal fringe of Emae. Informants stated that increased erosion and sea level rise had taken place transforming the shoreline. An informant captures this sentiment:

So one of the biggest problems at this time is sea level rise is affecting all the coastal areas, especially people that live close to the coastline. Our road is damaged and then the sea starts to move in. It moves very fast, very fast (EP).

Consistently, reinforced concrete structures, either communal or private, are well known to be "safe houses" 
in villages on Emae. For example, around Safuti village the school is known as "safe house." The Emae Disaster Chairman responded when asked about evacuation centers: "We don't have an evacuation center. We must run through all classrooms and hide" (DM 3). Other prominent themes that emerged were the loss of coastal tree cover (a long-term process exacerbated by cyclone Pam) and damaged communication infrastructure during and after cyclone Pam. As such, respondents suggested an increased susceptibility to coastal hazards and the need to address the inadequate communications systems.

The cultural dimension of susceptibility is defined as the potential for damage to intangible values including meanings placed on artefacts, customs, habitual practices, and natural or urban landscapes. During interviews, this was expressed by impacts on traditional customary items, such as yams, bananas, kava, mats, and pigs. Cyclone Pam uprooted and "spoiled" yams, banana trees were stripped bare, kava was destroyed by salt spray, wild cane used to make mats were destroyed, and pigs were killed or escaped from their enclosures. All of these plants and animals have been further impacted by drought, and locals explained that culturally important resources have been detrimentally affected by hazards in the past. Intangible values affected were numerous as there is little separation of human systems and nature. Damage to the reefs, crops, trees, animals, and settlements affect cultural practices. For example, kava, wiped out from salt spray, is a root crop that when prepared and consumed represents custom and respect. As such, the widespread loss of ecosystem services was suggested to have severely impacted everyday cultural practices due to a lack of traditional food availability, but further, as identity is defined and lived through culturally important goods and practices a loss of key customary elements has impacted the overall well-being of Emae communities. This was especially evident during a chief's funeral where the scarcity of customary goods led to diminished offerings by neighboring communities, for example.

The environmental dimension is the potential of damage to ecological and biophysical systems and their function (for example, ecosystem services). Despite cyclone Pam's impacts occurring 11 months prior to our fieldwork with severe disruptions to ecosystem services, local informants indicated that climate change (which includes extreme weather events), particularly perceived changes in the hydrological cycle and the depletion of coastal resources, was their most prominent environmental concern. Regional, national, and local stakeholders all regarded climate change as a main environmental process that affects disaster vulnerability. The theme of environmental impacts from climate change can be expressed through this response, whereby:
The issue with climate change is the big one, and it affects mostly our marine resources. Coral reefs are starting to die, and also the fish. If you go out to the reef the salt water has become warm, and also, sea level rise (EP).

Cyclone Pam destroyed crops that Emae residents depend on for nutrition, and as such local fisheries became the most prominent food security asset. Increased pressure on the inside reefs by communities after Cyclone Pam was a major concern with strategies in place to encourage communities to venture further for subsistence, although all professional fishermen catch deep water fish such as Tuna (EP). Human pressure was suggested by informants to have been steadily increasing on coastal resources (including fresh water) from increased demand after disasters and general population growth. Moreover, government and local stakeholders suggest warming oceans and acidification is compounding extant human pressures.

The institutional dimension is the potential damage to governance systems, formal and informal, due to exposed weakness following a disaster. Community disputes were suggested to be impacting development planning. There was reference to the recovery after cyclone Pam, for example, when community disputes were driven by aid allocation (for instance, water systems connected in certain villages but not others). Village chiefs mentioned that the Council of Chiefs (Ngarikitu) meetings, which are meant to address Emae's current and future needs, were dominated by community disputes over land and resources at the time of our field interviews. Community disputes are present in some islands around Vanuatu, but not in all. An informant's response about the core differences between his home of Pentecost and Emae, where he currently works, was revealing: "Emae dispute more; Pentecost not so much" (E2). While informants acknowledged the deleterious impact that disputes have on long-term development (including DRR) planning, at the time of our interviews solutions appeared a long way off. Informal discussions and interviews revealed other important themes: first, there was a perception of unresponsive national and provincial level governments, which informants said leaves them feeling isolated; second, data suggested a growing dependence on relief after disasters to the detriment of a championed ideal of self-reliance; and last, an overall changing community dynamic towards western values and beliefs. This is perceived as a source of positive change (for example, education and health), but is also considered by many elders as undermining traditional social structures, thereby leading to conflict between old and new institutions. 


\section{Livelihood Resilience as Attributes that Can Reduce Vulnerability}

The adapted framework posits that people's livelihood resilience is a critical component of vulnerability and therefore crucial to understand if vulnerability is to be reduced. While resilience indicators can often be more positive in nature, there can also be, at times, limits and deficiencies of these resilience elements. Key indicators of livelihood resilience are summarized in Table 3.

Knowledge, information, and resource flows are considered key components of livelihood resilience (Tanner et al. 2014). People on Emae rely on both traditional and contemporary sources of information and knowledge. Traditional practices and institutions, such as chiefs and kinship relationships, remain dominant, but it was reported, and observed, that contemporary structures were becoming more important. This was most visible through provincial government institutions such as the area councils and secretaries and community level committees (for example, women, disaster, water, education). Emae locals indicated that they have been receptive to external information from government and NGO sources, particularly in relation to climate change information. The way formal external information enters Emae was captured through this response by a disaster committee member:

Information comes in, when NDMO [National Disaster Management Office] people, or Red Cross, or Save the Children, when they come, they go through the area secretary [Provincial government representative]. So they go through the area council and then the area council contacts all the responsible persons, like chiefs, or health committees, or disaster committees and then we organize all the people together, then everyone comes to the nakamal [traditional meeting place] and then we talk to them. That's how information flows (DM).

Resources flow inside and outside formal governance channels. Goods, ideas, and information travel through kinship groups in the capital, Port Vila, to Emae Island. There was evidence that NGOs and governments provide material support, although there was greater emphasis on informal support systems. The reliance on informal social protection observed on Emae, and in the extensive Emae diaspora in Port Vila, is supported by other research in the Pacific (Ratuva 2014). Strong informal social support was presented as a positive action, not only due to a lack of formal assistance, but because of the connection to custom.

Table 3 Indicators of livelihood resilience in Emae communities

\begin{tabular}{|c|c|}
\hline Indicators of livelihood resilience & Examples from the data \\
\hline Knowledge, information, and resource flows & $\begin{array}{l}\text { Acceptance of externally derived information/knowledge } \\
\text { Traditional and modern knowledge } \\
\text { Limited government and agencies support (framed positively } \\
\text { and negatively by informants) } \\
\text { Education and awareness raising }\end{array}$ \\
\hline $\begin{array}{l}\text { Participation in informal and formal } \\
\text { decision-making process }\end{array}$ & $\begin{array}{l}\text { Community committees (for example, disaster, water, women) } \\
\text { Policy forums and feedback } \\
\text { Chiefs as main decision makers } \\
\text { Free national elections }\end{array}$ \\
\hline Capabilities, agency, assets, and activities & $\begin{array}{l}\text { "Taboo" (no access) coastal areas } \\
\text { Community-based conservation management } \\
\text { CCA agricultural initiatives } \\
\text { Planning through traditional/modern institutions }\end{array}$ \\
\hline Social capital & $\begin{array}{l}\text { Fundraising for collective causes } \\
\text { Collective action (road clearing/response) } \\
\text { Family networks/support } \\
\text { Sharing information and resources }\end{array}$ \\
\hline Human rights & $\begin{array}{l}\text { Access to water, land, and resources } \\
\text { Access to education and healthcare } \\
\text { Freedom from persecution } \\
\text { Lacking women empowerment }\end{array}$ \\
\hline
\end{tabular}


Participation in formal and informal decision-making processes relates to how decisions are made inside communities, while also accounting for macro decisions that may affect them. Emae society is patriarchal and hierarchical with the chiefs constituting the final decision makers. This has serious ramifications for the women (and to lesser extent lower rank men) of Emae, whereby they are excluded from major decision making. This example is a case in point of the limitations of using a "positive" framing of resilience for these societal attributes increase many dimensions of susceptibility (returned to in the discussion). Despite limitations of this nature, communities do discuss most issues democratically, as for example through the process of planning:

With all planning, how now we need all water, work on all new development that happen here. We all meet, we have a big general meeting, community, chief, and the council [of chiefs], we with the community meet and talk about all new planning and projects that will happen in the community (DC).

But to reinforce that the chief is always the center of the decision-making process, this response is pertinent: "But suppose you work without chief, no one will know. So, you must work with the chief. That's how the community works" (DC). Regarding participation in national or even provincial government decision making, it was found that while there was a certain level of distrust, many Emae islanders felt that government agencies were beginning to accept the importance of community input. Emerging evidence was found of inclusive community consultation processes for water security projects as well as new fishing and mining policies.

Capabilities, assets, and activities to make a living are vital for assessing livelihood resilience (Tanner et al. 2014). Communities on Emae have differing capabilities, assets, and activities to sustain livelihoods. Although idiographic to some extent, island-scale themes did emerge that are broadly representative of all Emae communities. For example, the theme of conservation management was prominent in the data with many communities actively involved. This informant's response captures the theme:

Trying to make some conservation, we have a taboo area, a no access area. And then some small management so they understand that it helps in the next five to ten years to come. But at the same time we help all together with replanting and also protecting, so in the future people can still eat fish (EP).

Emae communities, along with environmental stakeholders, are intimately aware of their livelihood assets and are beginning to address the large scale environmental and social challenges. Previous strategies include a successful malaria eradication program $(\mathrm{H})$, ongoing coastal replanting (DC), crop diversification, and increased market-based livelihood strategies (EP).

There was evidence of high levels of social capital in the communities on Emae, including both intra- and intercommunity support and collaboration. The most prominent example that emerged was the experience of clearing the coastal road of debris after cyclone Pam. The experience was retold by multiple informants, but this response succinctly captures what occurred on the south coast of Emae:

We had three communities that worked together, starting from the other side then right to here. So we helped, children, mammas, papas, everyone moved together. We didn't wait for the government (DM).

Other key examples of social capital were witnessed through family support (for example, places to stay for children who want to pursue post year 10 education in Port Vila), fundraising for local and island-wide causes, remittances, and an identified resource sharing that has taken place in times of scarcity (as was the case during El Niño at the time of the fieldwork).

The concept of livelihood resilience is underpinned by human rights. During fieldwork, we observed that Emae communities were free from persecution and free to practise their beliefs. All Emae inhabitants have access to water and land to sustain themselves, but as presented above, informants were concerned by a lack of water and food security due to the impact of cyclone Pam and the El Niño drought. Education and healthcare are available, but are not free and in times of physical or economic shock (like cyclone Pam), paying for these services becomes very difficult. A common concern raised by observers is the lack of female empowerment in Vanuatu, and this was true for Emae. Although some of the women in Emae suggested that positive steps have been made, such as the addition of women's committees in all villages, much more remains to be done. Nevertheless, due to more opportunities in Port Vila, many educated young women leave and gain employment there, thus breaking the cycle of patriarchal structural dependency that many women continue to face.

\section{An Adapted Framework for Emae Island, Vanuatu}

This article uses an adapted MOVE framework as a heuristic tool to generate a working (not a complete) understanding of the causal factors of vulnerability that affect Emae communities. The underlying premise of the MOVE framework was kept, such as the thematic dimensions of vulnerability and their description, along with vulnerability as a function of exposure and physical and 
social susceptibility. But the MOVE framework has shortcomings. The most prevalent relates to the frameworks' limited ability to address the historical dimensions of disaster vulnerability. An historical perspective challenges "here and now" interpretations and provides the counterweight of historical circumstances that have led to risk accumulation whenever environmental hazards have interacted with social-ecological systems over time (Pelling 2003; Wisner et al. 2004, 2012; Oliver-Smith 2010).

When we examined the historical dimensions of disasters (Oliver-Smith 2010) on Emae, we discovered that villages had been relocated to the coastal fringe in the 1950s. This information is pertinent to understanding current day disaster exposure and risk, and is influencing decisions to return people to original village sites where current gardens are located. An example of the historical dimension of susceptibility is the relocation of Makatea village from its relatively safe inland location, to a new coastal area where it was subsequently decimated by a tsunami in 1978. Following the tsunami, the village moved further inland and has avoided serious exposure to coastal risks such as storm surges (including from the recent cyclone Pam). The addition of an historical dimension to susceptibility has allowed for an "over time analysis" that was missing in the MOVE framework.

The remaining dimensions of susceptibility revealed many key determinants of disaster vulnerability on Emae Island. Many are in line with previous research in small island developing states (SIDS), for example, limited economic opportunities and a dependence on exposed assets, namely fisheries and agriculture (Pelling and Uitto 2001; Betzold 2015). Yet other susceptibility attributes are specific to Emae, which has mostly avoided large-scale developments, such as tourism and other industries. It also remains a traditional society with little influence from, or over, the national government. In informal discussions, this was presented as both positive (independent) and negative (isolated). Water concerns dominated discussions, likely due to the severity of the El Niño drought that was in effect, although an "over time analysis" suggested that this has been a major issue at least since the 1950s. The particularities of groundwater vulnerability on small islands is now established in the literature (Holding et al. 2016), and this remains a major concern throughout the South Pacific. Severe hazard events, like cyclone Pam, reveal systemic issues such as a lack of evacuation centers, highly exposed roads, decreased coastal protection, and poor building design and construction. Longer term adaptations, which include village relocation, were discussed, although institutional susceptibilities that include community disputes over land, access to resources, and even disaster aid hamper more concerted, organized efforts to reduce this critical aspect of disaster risk. Furthermore, climate change was perceived as a significant threat with many references to increased impacts on fisheries and perceived changes in the hydrological cycle.

Our second addition to the framework was the replacement of lack of resilience with livelihood resilience. When livelihood resilience was considered on Emae, many beneficial strategies were identified: land and coastal management, community engagement through traditional and contemporary institutions, and strong bonding and bridging social capital demonstrated by communities helping each other, among others (Table 3). We posit that understanding livelihood resilience helps illuminate the structure and functioning of communities. For example, by understanding how knowledge, information, and resources flow in Emae, it becomes possible to formulate programs and strategies that build on strengths, while identifying weakness, or what the MOVE framework purports to be a "lack of resilience." This positive framing is more than cosmetic-it begins from a position of agency (Tanner et al. 2014), which suggests that communities are not passive but rather are aware of their complex vulnerabilities more broadly. This proactive awareness arises because communities face numerous threats of which disasters are one. Other threats are environmental (for example, climate change), social (for example, healthcare, education, jobs opportunities), cultural (for example, loss of traditions and identity), and political (for example, perceived lack of support from government), which aligns with the concept of multiple exposures from multiple threats (Kelman et al. 2015).

While livelihood resilience has been framed primarily as positive attributes in our disaster vulnerability framework, some societal attributes continue to lack resilience, such as the exclusion of women from major decisions and the inability to reduce many dimensions of susceptibility to risk. Application of our modified framework generated a more accurate level of livelihood resilience by both emphasizing the positive attributes while considering the present real limitations and negatives. Other attributes of livelihood resilience presented in our framework are more ambiguous and need further clarity than the current study provided. Examples include the receptivity to external ideas and interventions (may be positive or negative, it is contextual), traditional institutions (for example, patriarchal and conservative), and the rise in modern institutions (for example, powerful community members reinforcing their positions), among others.

Our adapted framework proved useful in helping systematize data collection and analysis that allowed a holistic picture of disaster vulnerability to emerge. For example, in the Emae case, participation in formal and informal decision making was mostly negative within the boundaries set by our framework, particularly in reference to gender- 
based exclusion. This would probably amount to an additional vulnerability component with implications for future DRR. The livelihood framework was highly beneficial in assessing vulnerability over time, because changes in community structure and function were reported and observed with implications for disaster risk. Our novel contribution lies with the data collected itself and with our demonstration of the importance of using a historical susceptibility dimension coupled with a livelihood framing of resilience to ensure vulnerability in its entirety is represented. This framework may serve as a useful tool for research, governments, and NGOs that often miss causality due to their initial position of disaster as a discrete event.

\section{Conclusion}

It is widely accepted that the societal costs from hazards are increasing around the world (UNISDR 2015), but there remains a multitude of paradigmatic variations surrounding what actually makes a society vulnerable (Cutter 1996; Lindell 2013). Although progress in science has led to an improved understanding of environmental hazards themselves, and technologies, such as satellites, have improved forecasting and risk mapping, there has been less focus on the causes of social vulnerability at the international level (Blanchard et al. 2015). This gap exists despite established research that has identified causal drivers of social vulnerability (Ribot 2011). Our study contributes to the growing literature that attempts to identify the causal social and physical disaster vulnerability factors by collecting and analyzing data from a small island developing state in the Pacific through a novel vulnerability framework.

An adapted MOVE framework was used to generate a working understanding of the causal factors of disaster vulnerability of communities living on Emae Island, Vanuatu. The MOVE framework considers disaster vulnerability as a function of exposure, susceptibility (socially, economically, physically, culturally, environmentally, institutionally) and a lack of resilience. The addition of the historical construction of vulnerability as a dimension of disaster vulnerability (Oliver-Smith 2010) and the substitution of livelihood resilience (Tanner et al. 2014) for the original "lack of resilience" concept in the MOVE model were the additions/changes made.

Fieldwork with Emae Island communities revealed high levels of exposure and susceptibility to hazards, but also identified high levels of livelihood resilience. This was evidenced through Emae's inhabitants support for their kin and communities after cyclone Pam (2015) and throughout the El Niño (2015/2016) drought that exacerbated food and water insecurity. Land and coastal management strategies were targeted as both long- and short-term goals and were driven by a combination of traditional and modern structures and institutions. While cyclone Pam destroyed the majority of agriculture and all but a few physical structures throughout Emae, communities drew on bonding social capital to respond and begin the recovery process. There were limitations to Emae's livelihood resilience, as seen primarily through a lack of female empowerment and the fact that many disaster susceptibilities had not been sufficiently addressed.

Our adapted MOVE framework helped interpret and structure the data collected to then showcase where shortcomings might lie in understanding causal factors of disaster vulnerability on Emae Island. Our additions/changes to the MOVE framework might indeed be relevant to other small islands in the Pacific and beyond.

Acknowledgements We would like to acknowledge the people of Emae Island, Vanuatu for their time, energy, and enthusiasm during the fieldwork. There were many other people in Vanuatu who made this research possible, particularly in the difficult times during the El Niño drought of 2015/2016. The lead author would particularly like to thank staff at the Vanuatu Cultural Centre, the Vanuatu National Advisory Board of Climate Change and Disaster Risk Reduction (NAB) along with other government agencies and NGOs based in Port Vila, Vanuatu. A special thank you goes to Raymond Manuake and the entire Manuake family, Laurena Coustard de Nerbonne, and all who helped along the way. This article was greatly improved by the comments and suggestions of two anonymous reviewers.

Open Access This article is distributed under the terms of the Creative Commons Attribution 4.0 International License (http://crea tivecommons.org/licenses/by/4.0/), which permits unrestricted use, distribution, and reproduction in any medium, provided you give appropriate credit to the original author(s) and the source, provide a link to the Creative Commons license, and indicate if changes were made.

\section{References}

Aitsi-Selmi, A., S. Egawa, H. Sasaki, C. Wannous, and V. Murray. 2015. The sendai framework for disaster risk reduction: Renewing the global commitment to people's resilience, health, and well-being. International Journal of Disaster Risk Science 6(2): 164-176.

Alexander, D.E. 2013. Resilience and disaster risk reduction: An etymological journey. Natural Hazards and Earth System Science 13(11): 2707-2716.

Barnett, J. 2010. Dangerous climate change in the Pacific islands: Food production and food security. Regional Environmental Change 11(S1): 229-237.

Betzold, C. 2015. Adapting to climate change in small island developing states. Climatic Change 133(3): 481-489.

Birkmann, J., O.D. Cardona, M.L. Carreño, A.H. Barbat, M. Pelling, S. Schneiderbauer, S. Kienberger, M. Keiler, et al. 2013. Framing vulnerability, risk and societal responses: The MOVE framework. Natural Hazards 67(2): 193-211.

Blanchard, K., A. Aitsi-Selmi, and V. Murray. 2015. The Sendai framework on disaster risk reduction: From science and technology to societal resilience. International Journal of 
Disaster Resilience in the Built Environment 6(2). https://doi. org/10.1108/IJDRBE-04-2015-0019.

Bogard, W.C. 1988. Bringing social theory to hazards research: Conditions and consequences of the mitigation of environmental hazards. Sociological Perspectives 31(2): 147-168.

Boruff, B.J., and S.L. Cutter. 2007. The environmental vulnerability of Caribbean Island nations. Geographical Review 97(1): 24-45.

Briguglio, L. 1995. Small island developing states and their economic vulnerabilities. World Development 23(9): 1615-1632.

Cai, W., S. Borlace, M. Lengaigne, P. van Rensch, M. Collins, G. Vecchi, A. Timmermann, A. Santoso, et al. 2014. Increasing frequency of extreme El Nino events due to greenhouse warming. Nature Climate Change 4(2): 111-116.

Capell, A. 1962. The Polynesian language of Mae (Emwae), New Hebrides. Auckland: Linguistic Society of New Zealand.

Cardona, O.D., M.K. van Aalst, J. Birkmann, M. Fordham, G. McGregor, R. Perez, R.S. Pulwarty, E.L.F. Schipper, et al. 2012. Determinants of risk: Exposure and vulnerability. In Managing the risks of extreme events and disasters to advance climate change adaptation, ed. C.B. Field, V. Barros, T.F. Stocker, D. Qin, D.J. Dokken, K.L. Ebi, M.D. Mastrandrea, K.J. Mach, et al., 65-108. Cambridge, UK: Cambridge University Press.

Chambers, R. 1989. Editorial introduction: Vulnerability, coping and policy. IDS Bulletin 20(2): 1-7.

Cobon, D.H., M. Ewai, K. Inape, and R.M. Bourke. 2016. Food shortages are associated with droughts, floods, frosts and ENSO in Papua New Guinea. Agricultural Systems 145: 150-164.

Connell, J. 2010. Pacific islands in the global economy: Paradoxes of migration and culture. Singapore Journal of Tropical Geography 31(1): 115-129.

Connell, J. 2015. Vulnerable islands: Climate change, tectonic change, and changing livelihoods in the Western Pacific. The Contemporary Pacific 27(1): 1-36.

Cutter, S.L. 1996. Vulnerability to environmental hazards. Progress in Human Geography 20(4): 529-539.

Cutter, S.L., L. Barnes, M. Berry, C. Burton, E. Evans, E. Tate, and J. Webb. 2008. A place-based model for understanding community resilience to natural disasters. Global Environmental Change 18(4): 598-606.

Cutter, S.L., B.J. Boruff, and W.L. Shirley. 2003. Social vulnerability to environmental hazards. Social Science Quarterly 84(2): 242-261.

Depietri, Y., T. Welle, and F.G. Renaud. 2013. Social vulnerability assessment of the Cologne urban area (Germany) to heat waves: Links to ecosystem services. International Journal of Disaster Risk Reduction 6: 98-117.

Djalante, R., C. Holley, F. Thomalla, and M. Carnegie. 2013. Pathways for adaptive and integrated disaster resilience. Natural Hazards 69(3): 2105-2135.

Dunn, K. 2000. Interviewing. In Qualitative research methods in human geography, ed. I. Hay, 50-82. Melbourne: Oxford University Press.

Encontre, P. 1999. The vulnerability and resilience of small island developing states in the context of globalization. Natural Resources Forum 23(3): 261-270.

Eriksen, S.H., and K. O'Brien. 2007. Vulnerability, poverty and the need for sustainable adaptation measures. Climate Policy 7(4): 337-352.

Ferdinand, I., G. O'Brien, P. O'Keefe, and J. Jayawickrama. 2012. The double bind of poverty and community disaster risk reduction: A case study from the Caribbean. International Journal of Disaster Risk Reduction 2: 84-94.

Folke, C. 2006. Resilience: The emergence of a perspective for social-ecological systems analyses. Global Environmental Change 16(3): 253-267.
Fuller, A.T., and S. Pincetl. 2014. Vulnerability studies: A bibliometric review. The Professional Geographer 67(3): 319-329.

Gaillard, J.C., and J. Mercer. 2012. From knowledge to action: Bridging gaps in disaster risk reduction. Progress in Human Geography 37(1): 93-114.

Garschagen, M., M. Hagenlocher, M. Comes, M. Dubbert, R. Sabelfeld, Y.J. Lee, L. Grunewald, M. Lanzendörfer, et al. 2016. World risk report. Bündnis Entwicklung Hilft (Alliance Development Works) and United Nations University - Institute for Environment and Human Security (UNU-EHS). http:// weltrisikobericht.de. Accessed Nov 2016.

Hansen, G., and D. Stone. 2015. Assessing the observed impact of anthropogenic climate change. Nature Climate Change 6(5): 532-537.

Hewitt, K. 1983. Interpretations of calamity from the viewpoint of human ecology. London: Allen \& Unwin.

Holding, S., D.M. Allen, S. Foster, A. Hsieh, I. Larocque, J. Klassen, and S.C. Van Pelt. 2016. Groundwater vulnerability on small islands. Nature Climate Change 6(12): 1100-1103.

Holling, C.S. 1973. Resilience and stability of ecological systems. Annual Review of Ecology and Systematics 4: 1-23.

Ifejika Speranza, C., U. Wiesmann, and S. Rist. 2014. An indicator framework for assessing livelihood resilience in the context of social-ecological dynamics. Global Environmental Change 28: $109-119$

Jauhola, M. 2015. Scraps of home. Asian Journal of Social Science 43(6): 738-759.

Julca, A., and O. Paddison. 2009. Vulnerabilities and migration in small island developing states in the context of climate change. Natural Hazards 55(3): 717-728.

Kablan, M.K.A., K. Dongo, and M. Coulibaly. 2017. Assessment of social vulnerability to flood in urban Côte d'Ivoire using the MOVE framework. Water 9(4): 292-310.

Kates, R.W. 1971. Natural hazard in human ecological perspective: Hypotheses and models. Economic Geography 47(3): 438-451.

Kelman, I. 2012. Disaster diplomacy. Abingdon, Oxon: Routledge.

Kelman, I. 2014. No change from climate change: Vulnerability and small island developing states. The Geographical Journal 180(2): 120-129.

Kelman, I., J.C. Gaillard, and J. Mercer. 2015. Climate change's role in disaster risk reduction's future: Beyond vulnerability and resilience. International Journal of Disaster Risk Science 6(1): 21-27.

Knutson, T.R., J.L. McBride, J. Chan, K. Emanuel, G. Holland, C. Landsea, I. Held, J.P. Kossin, et al. 2010. Tropical cyclones and climate change. Nature Geoscience 3(3): 157-163.

Lavell, A., and A. Maskrey. 2014. The future of disaster risk management. Environmental Hazards 13(4): 267-280.

Lewis, J. 1990. The vulnerability of small island states to sea level rise: The need for holistic strategies. Disasters 14(3): 241-249.

Lewis, J. 2014. The susceptibility of the vulnerable: Some realities reassessed. Disaster Prevention and Management 23(1): 2-11.

Lindell, M.K. 2013. Disaster studies. Current Sociology 61(5-6): $797-825$

Mannakkara, S., and S.J. Wilkinson. 2015. Supporting post-disaster social recovery to build back better. International Journal of Disaster Resilience in the Built Environment 6(2): 126-139.

Méheux, K., D. Dominey-Howes, and K. Lloyd. 2006. Natural hazard impacts in small island developing states: A review of current knowledge and future research needs. Natural Hazards 40(2): 429-446.

Morrow, B.H. 1999. Identifying and mapping community vulnerability. Disasters 23(1): 1-18.

Noy, I. 2015. Natural disasters in the Pacific island countries: New measurements of impacts. Natural Hazards 84(S1): 7-18. 
O'Brien, K., S. Eriksen, L.P. Nygaard, and A.N.E. Schjolden. 2007. Why different interpretations of vulnerability matter in climate change discourses. Climate Policy 7(1): 73-88.

O'Keefe, P., K. Westgate, and B. Wisner. 1976. Taking the naturalness out of natural disasters. Nature 260(5552): 566-567.

Oliver-Smith, A. 2010. Haiti and the historical construction of disasters. New York: North American Congress on Latin America, Inc.

Oliver-Smith, A. 2013. Disaster risk reduction and climate change adaptation: The view from applied anthropology. Human Organization 72(4): 275-282.

Oliver-Smith, A., I. Alcántara-Ayala, I. Burton, and A. Lavell. 2016. Forensic investigations of disasters (FORIN): A conceptual framework and guide to research. In IRDR FORIN Publication No.2. Beijing: Integrated Research on Disaster Risk.

Olsson, L., A. Jerneck, H. Thoren, J. Persson, and D. O'Byrne. 2015. Why resilience is unappealing to social science: Theoretical and empirical investigations of the scientific use of resilience. Science Advances 1(4): e1400217.

Özerdem, A., and R. Bowd (eds.). 2009. Participatory research methodologies: Development and post-disaster/conflict reconstruction. Burlington, VT: Ashgate.

Paton, D., and D. Johnston. 2001. Disasters and communities: Vulnerability, resilience and preparedness. Disaster Prevention and Management: An International Journal 10(4): 270-277.

Pelling, M. 2003. The vulnerability of cities: Natural disasters and social resilience. Sterling, VA: Earthscan.

Pelling, M., and J.I. Uitto. 2001. Small island developing states: Natural disaster vulnerability and global change. Environmental Hazards 3(2): 49-62.

Quarentelli, E.L. 1987. Disaster studies: An analysis of the social historical factors affecting the development of research in the area. International Journal of Mass Emergencies and Disasters 5(3): 285-310.

Ratuva, S. 2014. "Failed" or resilient subaltern communities? Pacific indigenous social protection systems in a neoliberal world. Pacific Journalism Review 20(2): 40-58.

Ray-Bennett, N.S. 2009. The influence of caste, class and gender in surviving multiple disasters: A case study from Orissa, India. Environmental Hazards 8(1): 5-22.

Ribot, J. 2011. Vulnerability before adaptation: Toward transformative climate action. Global Environmental Change 21(4): $1160-1162$.

Schipper, L., and M. Pelling. 2006. Disaster risk, climate change and international development: Scope for, and challenges to, integration. Disasters 30(1): 19-38.

Schischka, J., P. Dalziel, and C. Saunders. 2008. Applying Sen's capability approach to poverty alleviation programs: Two case studies. Journal of Human Development 9(2): 229-246.

Semali, L.M., R.M. Ackerman, S.G. Bradley, C.N. Buzinde, M.L. Jaksch, J.M. Kalavar, V. Montecinos, and M.R. Chinoy. 2007. Developing excellence in indigenously informed research. AlterNative: An International Journal of Indigenous Scholarship 3(2): 8-23.
Solomon, S.M., and D.L. Forbes. 1999. Coastal hazards and associated management issues on South Pacific Islands. Ocean \& Coastal Management 42(6-7): 523-554.

SPC (Secretariat of the Pacific Community). 2015. Vanuatu climate change and disaster risk reduction policy 2016-2030. Suva, Fiji. http://www.preventionweb.net/files/46449_vanuatuccdrrpo licy2015.pdf. Accessed 12 Aug 2016.

Tanner, T., D. Lewis, D. Wrathall, R. Bronen, N. Cradock-Henry, S. Huq, C. Lawless, R. Nawrotzki, et al. 2014. Livelihood resilience in the face of climate change. Nature Climate Change 5(1): 23-26.

Tobin, K.A. 2013. Population density and housing in Port-au-Prince: Historical construction of vulnerability. Journal of Urban History 39(6): 1045-1061.

Turvey, R. 2007. Vulnerability assessment of developing countries: The case of small-island developing states. Development Policy Review 25(2): 243-264.

UNISDR (United Nations International Strategy for Disaster Risk). 2015. Sendai framework for disaster risk reduction 2015-2030. http://www.unisdr.org/we/coordinate/sendai-framework. Accessed 12 Aug 2016.

Vo, C. 2015. Vulnerability and resiliency: How climate disasters activate latent social assets. International Social Work 58(3): 421-434.

Walsh, K. 2015. Fine resolution simulations of the effect of climate change on tropical cyclones in the South Pacific. Climate Dynamics 45(9-10): 2619-2631.

Watts, M.J., and H.G. Bohle. 1993. The space of vulnerability: The causal structure of hunger and famine. Progress in Human Geography 17(1): 43-67.

Weichselgartner, J. 2001. Disaster mitigation: The concept of vulnerability revisited. Disaster Prevention and Management: An International Journal 10(2): 85-95.

Weichselgartner, J., and P. Pigeon. 2015. The role of knowledge in disaster risk reduction. International Journal of Disaster Risk Science 6(2): 107-116

Welle, T., Y. Depietri, M. Angignard, J. Birkmann, F. Renaud, and S. Greiving. 2014. Vulnerability assessment to heat waves, floods, and earthquakes using the MOVE framework: Test case Cologne, Germany. In Assessment of vulnerability to natural hazards: A European perspective, ed. J. Birkmann, S. Kienberger, and D.E. Alexander, 91-124. Amsterdam: Elsevier.

Westoby, P. 2010. Dialogue and disentanglement: Navigating tensions for sustainable community economic development within Vanuatu. The International Journal of Environmental, Cultural, Economic and Social Sustainability 6(1): 81-92.

Wisner, B., P.M. Blaikie, T. Cannon, I. Davies. 2004. At risk: Natural hazards, people's vulnerability, and disasters. 2nd edn. London: Routledge.

Wisner, B., J.C. Gaillard, and I. Kelman. 2012. The Routledge handbook of hazards and disaster risk reduction. Abingdon, Oxon: Routledge. 